\title{
O estudo dirigido como estratégia de ensino na educação profissional em enfermagem*
}

\author{
DIRECTED STUDY AS A TEACHING STRATEGY IN NURSING EDUCATION \\ ELESTUDIO DIRIGIDO COMO ESTRATEGIADE ENSEÑANZA EN LA \\ EDUCACIÓN PROFESIONAL EN ENFERMERÍA
}

\author{
Eliana Suemi Handa Okane ${ }^{1}$, Regina Toshie Takahashi ${ }^{2}$
}

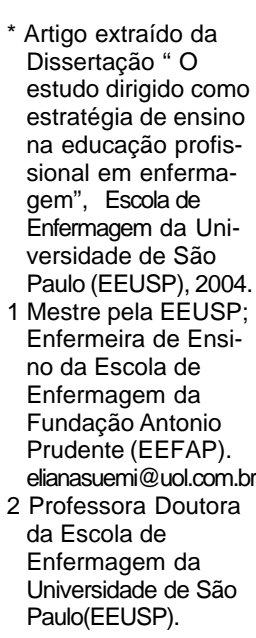

Artigo extraído da Dissertação "O estudo dirigido como sional em enfermagem", Escola de Enfermagem da UniPaulo (EEUSP), 2004 1 Mestre pela EEUSP; Enfermeira de EnsiEnfermagem de Fundação Antonio Prudente (EEFAP) elianasuemi@uol.com.br

da Escola de Universidade de Săo Paulo(EEUSP).

\section{RESUMO}

Estudo exploratório-descritivo, objetivou avaliar o estudo dirigido como estratégia de ensino na educação profissional. Para a coleta de dados, foi aplicado um questionário a 14 alunos de um curso de uma mesma turma de Técnico de Enfermagem. As respostas foram analisadas segundo Bardin. $\mathrm{O}$ conceito atribuído à estratégia foi bom $86 \%$. Foram identificadas 83 unidades semânticas na análise das respostas, categorizadas em: vantagens (53\%); não "legal" (16\%); dificuldades $(7 \%)$; sentimentos (12\%) e sugestões (12\%). Além disso, os sujeitos avaliaram como propósitos didático pedagógicos do estudo dirigido permitir desenvolver temas de interesse do aluno; estimular o prazer em estudar e incentivar o aluno a ser o sujeito de seu aprendizado. As autoras consideram que o estudo dirigido é uma boa estratégia de ensino, possuindo peculiaridades que exigem habilidade e competência dos docentes e discentes para a obtenção de resultados satisfatórios no processo ensino/ aprendizado.

\section{DESCRITORES}

Educação em enfermagem.

Ensino (métodos).

Educação profissionalizante.

\section{ABSTRACT}

This is a descriptive exploratory study aimed at evaluating directed study as a teaching strategy used in professional education. Data was collected by means of a questionnaire applied to 14 students attending a Practical Nursing course; their answers were examined according to Bardin. The strategy was considered good (86\%). Eightythree semantic units were identified in the analysis of the answers, classified as: advantages $(53 \%)$; not "nice" (16\%); difficulties (7\%); feelings (12\%); and suggestions (12\%). In addition, subjects considered as didactic educational purposes of direct study to allow the development of topics that interest the student; to stimulate pleasure in studying; and to encourage the student to be the subject of his own learning process. The authors consider directed study a good teaching strategy, with features that demand skills and competences from teachers and students in order to obtain satisfactory results in the teaching-learning process.

\section{KEY WORDS}

Nursing education.

Teaching (methods).

Education, professional.

\section{RESUMEN}

Estudio exploratorio-descriptivo que tuvo como objetivo evaluar el estudio dirigido como estrategia de enseñanza en la educación profesional. Para la recolección de los datos, fue aplicado un cuestionario a 14 alumnos del curso de una misma promoción de Técnicos deEnfermería. Las respuestas fueron analizadas según Bardin. El concepto atribuido a la estrategia fue bueno en el $86 \%$. Fueron identificadas 83 unidades semán-ticas en el análisis de las respuestas, categorizadas en: ventajas (53\%); no "malo" (16\%); dificultades (7\%); sentimientos (12\%) y sugerencias (12\%). Además de eso los sujetos evaluaron como propósitos didácticos pedagógicos del estudio dirigido, permitir desarrollar temas de interés del alumno, estimular el placer para estudiar e incentivar al alumno a ser sujeto de su aprendizaje. Las autoras consideran que el estudio dirigido es una buena estrategia de enseñanza, que posee peculiaridades que exigen habilidad y competencia de los docentes y discentes para la obtención de resultados satisfactorios en el proceso enseñaza/aprendizaje.

\section{DESCRIPTORES}

Educación en enfermería. Enseñanza (métodos). Educación profesionalizante. 


\section{INTRODUÇÃO}

A prática profissional como enfermeiras de ensino em uma escola de educação profissional para auxiliares e técnicos de enfermagem na cidade de São Paulo, desde 1998, trouxeram-nos muitas inquietações que resultaram em desafios para desenvolver habilidades e competências ao exercer as atribuições de professoras.

Dentre os desafios, percebemos que a interação professor-aluno em sala de aula é de grande importância, por observar a interferência direta dessa interação nos resultados do processo ensino-aprendizado.

Assim, reflexões a respeito do assunto aproximaram-nos das estratégias de ensino, sendo a escolha destas ações diretamente ligadas à intenção educativa e aos resultados do processo ensino-aprendizado, proporcionalmente melhores na medida em que houver melhor interação professor-aluno, aluno-aluno e aluno-consigo mesmo, em sala de aula, para o desenvolvimento das atividades didático-pedagógicas.

As estratégias são ações que visam facilitar a obtenção e multiplicar o rendimento e a qualidade dos resultados do processo ensino-aprendizado ${ }^{(1)}$.

$\mathrm{Na}$ escolha das estratégias de ensino, existe a necessidade das transformações das diretrizes do ensino, na qual o aluno e não o professor assume o centro de todas as atividades, nos quais

(...) suas necessidades e de seu progresso físico, intelectual, moral e social, que deve ser planejado todo o trabalho de educação ${ }^{(2)}$.

\section{Ou:}

(...) compete às escolas a procura de novos métodos de ensino que desenvolvam no aluno qualidades necessárias aos papéis que irá desempenhar na sociedade $(. . .)^{(3)}$

Podemos observar que desde 1968, discute-se as transformações das diretrizes de ensino e a necessidade de desenvolver novos métodos de ensino nas escolas para atender a uma nova sociedade. Trata-se de um processo longo onde ainda estamos trabalhando, não havendo muita literatura sobre o assunto, principalmente envolvendo a educação profissional. As estratégias de ensino são vistas como função das outras três fases do processo educacional, não sendo muito utilizadas como objeto de estudo ${ }^{(4)}$.

Em especial, na área de ensino da educação profissional em enfermagem, estão ocorrendo mudanças no processo educacional, decorrentes das prescrições da legislação vigente, entre outros motivos.
(....) A educação profissional assim concebida não se confunde com a educação básica ou superior. Destina-se àqueles que necessitam se preparar para seu desempenho profissional, num sistema de produção de bens e de prestação de serviços, onde não basta somente o domínio da informação, por mais atualizada que seja. Deve, no entanto, assentar-se em sólida educação básica, ferramenta essencial para que o cidadão-trabalhador tenha efetivo acesso às conquistas tecnológicas da sociedade, pela apropriação do saber que alicerça a prática profissional, isto é, o domínio da "inteligência do trabalho" essas exigências são regidas pela Lei Federal n 9.394/96, de Diretrizes e Bases da Educação Nacional (LDB) ${ }^{(5)}$.

A essas mudanças prescritas pela LDB n 9.394/96 são atribuídos valores, objetivos e finalidades ao processo educacional, que quebram a hegemonia daquele que domina o conhecimento sobre o que executa as atividades no mundo do trabalho.

Por outro lado, no mundo do trabalho, fala-se deste domínio da inteligência a todos os elementos da equipe, ou seja, não existe espaço nesta sociedade para mão de obra não qualificada, o que compreende um modo de produção mais eficiente e eficaz, alicerçado na apropriação do saber.

Essas mudanças promovem, ao nosso ver, uma nova relação aluno-professor e um processo ensino-aprendizado inovador e dotado de necessidades que o ensino precisa prover para atender a essas exigências do mundo do trabalho, histórico, político, filosófico e social que se darão nas relações entre todos.

Para essa prática prescrita na LDB, os referenciais curriculares do Ministério da Educação e Cultura (MEC - 2000) ${ }^{(6)}$ orientam e indicam a aplicabilidade desses conteúdos:

- A adoção de desenhos curriculares e de alternativas metodológicas inovadoras, dinâmicas, que substituam o modelo centrado nas aulas tradicionais, de forma quase que exclusiva ou com ênfase absoluta, por um ambiente pedagógico caracterizado por "aulas operatórias", por workshops e oficinas nas quais os alunos trabalhem em projetos concretos e experimentais característicos da área, por oferecer espaços de discussão fundamentada do que está fartamente disponível para ser ouvido, visto e lido no mundo fora do espaço escolar, por seminários e palestras com profissionais atuantes, por visitas culturais e técnicas;

- A busca de alternativas de gestão de recursos educacionais, tais como acordos, convênios, patrocínios ou parcerias, que viabilizem constante renovação e atualização tecnológica para que a educação profissional faça parte da efetiva realidade do processo de trabalho da área;

- A criação de modelos pedagógicos que reflitam o dia-a-dia do profissional utilizando laboratórios dotados de aparato tecnológico que esteja em concordância com a atualidade do campo profissional; 
- A integração do ensino-serviço como forma de tornar o processo ensino aprendizagem aderido à realidade do trabalho;

- Estudo e a implantação de formas que facilitem a contratação de profissionais efetivamente engajados no trabalho adequando os esquemas pedagógicos e administrativos convencionais;

- A capacitação pedagógica do corpo docente, privilegiando processos pedagógicos crítico-reflexivo-participativo que auxilie os professores a desempenhar o papel de mediadores do processo ensino-aprendizagem ${ }^{(6)}$.

A LDB e as orientações das diretrizes curriculares são preocupações da Educação Nacional, constituindo-se em um desafio, não só aos professores, mas também a todos os envolvidos no palco deste cenário: os administradores, pedagogos e alunos. A prática é de difícil realização, visto que são necessários gastos e organização bem mais elevados e complexos do que exige o ensino tradicional. É preciso investir em recursos físicos, humanos, e de materiais adequados para que os resultados sejam os esperados ${ }^{(7)}$.

Frente a todos esses desafios para educar, acreditamos que escolher, desenvolver, aplicar e avaliar as estratégias de ensino em sala de aula é, sem dúvida, alternativa para melhorar a qualidade de ensino-aprendizagem na educação profissional. Porém, é preciso embasamento teórico-científico, ou seja, capacitação docente, além de investimentos nos recursos físicos e materiais.

\section{ESTRATÉGIAS DE ENSINO}

As terminologias utilizadas a seguir, para definir as estratégias de ensino são várias, entretanto, para o desenvolvimento deste estudo serão consideradas como sinônimos.

Estratégia é:

(....) toda organização e condução de ações e idéias (=como chego) para se alcançar um objetivo (=onde quero ir) a partir de uma situação dada (=onde estou) (...) poderíamos dizer que todos os procedimentos envolvidos no processo de ensino/aprendizagem podem ser considerados como estratégias. Assim, não deixa de ser uma estratégia a elaboração de objetivos, a determinação de conteúdos, a metodologia utilizada e a avaliação proposta, pois todos concorrem para a aprendizagem (...) No entanto, é costume e mais comum considerar estratégias de ensino os métodos ou atividades escolhidos no processo de ensino/aprendizagem $(\ldots . .)^{(8)}$

Estratégia de ensino pode ser definida como estratégia instrucional ou plano de ação didática, uma disposição ou maneira de utilizar métodos e técnicas de ensino, nos momentos metodológicos didáticos mais adequados, a fim de tornar o ensino e a conseqüente aprendizagem mais eficien- tes ao alcance dos objetivos visados ${ }^{(9)}$. Ou ainda, como métodos de ensino, quando os professores dirigem e estimulam o processo de ensino em função da aprendizagem dos alunos utilizando intencionalmente, um conjunto de ações, passos, condições externas e procedimentos ${ }^{(10)}$.

Portanto, as estratégias de ensino são ações didáticopedagógicas intencionais utilizadas para que se possa obter melhores resultados no processo ensino-aprendizado e envolvem as relações professor-aluno; aluno-aluno e aluno-consigo mesmo, imprescindíveis para o desenvolvimento cognitivo para aprender e ensinar.

A interação professor e aluno em sala de aula são carregadas de significados e valores, de intencionalidades, de subjetividades próprias de cada olhar ${ }^{(11)}$, refletindo e garantindo no processo ensino-aprendizado um olhar especial às estratégias de ensino, que ao nosso ver, é o "pano de fundo" que envolve todo o enredo, no qual contracenam os atores da Educação.

Para escolher e utilizar estratégias, o docente além de estudar e planejar embasado na teoria científica, deve somar criatividade e adaptações em suas ações didático-pedagógicas, por exemplo de jogos aos conteúdos de enfermagem.

\section{O ESTUDO DIRIGIDO}

O estudo dirigido não é um fato educativo isolado, mas parte de uma concepção pedagógica, uma continuidade de ações de todo o processo educacional.

O mau uso da estratégia observando que, quando seus princípios não estão esclarecidos, é muito provável sua má utilização. Muitas vezes é usado para deixar o aluno ocupado, sobretudo, se houver um professor responsável por várias séries em uma mesma classe, não existe nesta situação, nenhuma função didática programada e assistida ${ }^{(10)}$.

O estudo dirigido é um primeiro método ou técnica de ensino para tornar o educando independente do professor, orientando-o para estudos futuros e participação na sociedade. Os outros métodos para esta independência são o estudo supervisionado, onde há menor interferência do professor em relação ao estudo dirigido e às tarefas dirigidas, que constitui em terapêutica para eliminar ou atenuar deficiências ou suprir insuficiências constatadas na escolaridade do educando, e o estudo livre, em que o aluno trabalha completamente livre ${ }^{(9)}$.

O estudo dirigido apresenta duas funções principais; a primeira é de consolidação dos conhecimentos por meio de uma combinação da explicação do professor com exercícios. A segunda, é a busca da solução dos problemas por meio de questões que os alunos possam resolver criativamente e de forma independente ${ }^{(10)}$. 
Segundo esse autor ${ }^{(10)}$, esta estratégia de ensino procura:

- Desenvolver habilidades e hábitos de trabalho de forma independente e criativo;

- Sistematizar e consolidar conhecimentos, habilidades e hábitos;

- Possibilitar a cada aluno, individualmente, resolver problemas, vencer dificuldades e desenvolver métodos próprios de aprendizagem;

- Possibilitar aos alunos o desenvolvimento da capacidade de trabalhar, de forma livre e criativa, com os conhecimentos adquiridos, aplicando-os a situações novas, referentes a problemas cotidianos da sua vivência e a problemas mais amplos da vida social;

- Possibilitar ao professor a observação de cada aluno em suas dificuldades e progressos, bem como a verificação da eficácia do seu próprio trabalho na condução do ensino.

Cada aluno necessita de função distinta a ser desenvolvida no estudo dirigido, sendo o professor aquele que investiga as características desse aluno, sugerindo ações de acordo com elas e com o potencial de cada um.

O estudo dirigido fornece "balizamento didático" para o educando efetivar a sua aprendizagem, ao mesmo tempo em que vai conferindo técnicas e consciência de como estudar ${ }^{(9)}$.

Neste método, o professor serve de orientador e facilitador da aprendizagem para que cada aluno resolva de modo relativamente independente e criador a tarefa determinada. Tanto o professor quanto o aluno precisam obedecer condições prévias de estudo, planejamento e organização para participar do estudo dirigido ${ }^{(10)}$.

Para o aluno uma das condições é dominar as técnicas do trabalho, porém na educação profissional, observa-se que muitos apresentam deficiência no domínio dessas técnicas do trabalho, ou seja saber buscar, utilizando-se de recursos variados, ler, resumir, expor os resultados ${ }^{(10)}$, havendo necessidade de reforços nessa área para que o estudo flua sem maiores obstáculos.

Como educador, precisamos desenvolver, além do domínio técnico na área de atuação, a responsabilidade e a contribuição do ensino na formação de cidadãos que possuam uma perspectiva crítico-emancipadora do exercício profissional ${ }^{(12)}$.

Acreditamos que as relações no trabalho são transformadas devido as necessidades histórico-políticas atuais e iniciadas no processo ensino-aprendizado em sala de aula.

Atuar como docentes em sala de aula de forma diferente a que estávamos acostumados, e participar efetivamente dessas transformações, exige o desprendimento de velhos "conceitos" e o desenvolvimento de novas habilidades para ser competente nas relacionadas e nas ações a que nos propusermos desempenhar, considerando diferentes interesses e concepções de todos os atores envolvidos no processo ensino-aprendizado.

Nessa prática de transformação, o estudo dirigido é um bom exercício para desenvolver habilidades em busca dessas competências, tanto para o aluno como para o professor. Considerando que essa estratégia é o primeiro método ou técnica de ensino para tornar o educando independente do professor, orientando-o para estudos futuros e participação na sociedade ${ }^{(9)}$.

Existe uma relação entre superação dos modelos tradicionais na educação do profissional da saúde e conceitos da promoção da saúde versus a visão hospitalocêntrica ${ }^{(13)}$.

A adoção de estratégias inovadoras como a do estudo dirigido, poderá contribuir não apenas para o desenvolvimento de novas habilidades em relacionamento e atividade em sala de aula, mas também para promover novos conceitos para a assistência à saúde e as transformações nas relações na equipe de enfermagem em uma nova prática profissional, razão pela qual precisa ser avaliada.

Entendemos que as interações em sala de aula constroem o futuro profissional a qual se deseja formar, valorizando o trabalho em equipe, o respeito consigo e com o próximo, a auto estima e auto confiança. Sendo a estratégia de ensino parte de uma pedagogia libertadora.

Assim, o objetivo deste estudo foi identificar como os alunos de uma turma do Curso Técnico de Enfermagem de uma escola de educação profissional na cidade de São Paulo avaliaram a estratégia de ensino estudo dirigido que foi aplicada na Disciplina Saúde do Adulto.

\section{MÉTODO}

Trata-se de um estudo do tipo descritivo-exploratório que explora, observa, descreve e classifica as dimensões de uma estratégia de ensino na aprendizagem do aluno de um curso Técnico de Enfermagem ${ }^{(14)}$.

\section{Local}

A pesquisa foi realizada em uma Escola de Enfermagem formadora de auxiliares e técnicos de enfermagem, com especificidade curricular em Enfermagem Oncológica, mantida por um centro de referência em pesquisa e tratamento oncológico na cidade de São Paulo.

\section{População e critérios de inclusão}

A população constituiu-se de alunos de uma mesma turma, com formação básica profissional de auxiliar de enferma- 
gem e que concluíram o Curso de Habilitação Profissional de Técnico de Enfermagem.

Os critérios de inclusão dos alunos para compor a população foram:

- ter participado da estratégia de ensino, estudo dirigido, na Disciplina Saúde do Adulto;

- concordar em participar da pesquisa, assinando o termo de consentimento;

- estar presente no período determinado para a coleta de dados.

A análise das respostas, três sujeitos foram excluídos pelas seguintes razões:

- o primeiro sujeito avaliou o curso e não a estratégia de ensino;

- o segundo sujeito não respondeu à questão;

- o terceiro sujeito avaliou o estágio supervisionado e não a estratégia de ensino.

Portanto, dos dezessete alunos abordados, foram eleitos quatorze, que constituíram a população da pesquisa.

\section{Desenvolvimento da estratégia de ensino}

A estratégia de ensino foi aplicada no desenvolvimento dos temas da Disciplina Saúde do Adulto da IV Turma do Curso de formação de Técnico de Enfermagem.

Trata-se de um curso em que há aproveitamento de estudos para a formação no nível de técnico de enfermagem, ou seja, todos os alunos são auxiliares de enfermagem que realizam complementação para a formação de técnico de enfermagem. O curso constitui-se de 940 horas, tendo a Disciplina Saúde do Adulto 210 horas teórico-práticas e 170 horas práticas, ministradas no penúltimo bloco teórico do curso.

\section{Aplicação da estratégia em sala de aula}

A aplicação seguiu os seguintes passos:

- Apresentação da estratégia de ensino e de seus objetivos (conforme sub-item estudo dirigido)

- O cronograma de trabalho para o desenvolvimento da estratégia baseou-se em:

- tempo de preparo: cinco horas-aula, distribuídas em três dias;

- tempo para apresentação dos resultados: três horasaula, distribuídas em dois dias; com um tempo aproximado de dez minutos para a apresentação de cada aluno.
- Orientações para o desenvolvimento do estudo dirigido:

- determinar a escolha do tema, de acordo com o interesse e preferência do aluno, que envolvesse sua atuação profissional nas seguintes situações: pré-operatória, pósoperatória ou em Unidades de Terapia Intensiva;

- orientar as fontes de informação para o desenvolvimento do estudo, assim como a bibliografia;

- estabelecer os critérios de avaliação de desempenho;

- agendar com antecedência os contatos com o professor com a finalidade de discutir, esclarecer e direcionar, inclusive, a apresentação dos resultados, organização e planejamento didático-pedagógico;

- possibilitar a presença não obrigatória em sala de aula para o estudo.

Todos os temas desenvolvidos pelos alunos foram diferentes e estratégias para apresentação dos resultados do estudo dirigido, em sua maioria foi a preleção.

\section{Instrumento de coleta de dados}

Na elaboração do instrumento de coleta de dados, foram considerados: Thiollent ${ }^{(15)}$, para escolha do questionário como instrumento de coleta, onde o autor discute as técnicas de pesquisa sociológica estendida à Educação, ambas pertencentes à vertente ciência humana; Nerici ${ }^{(9)}$ inspirou a elaboração da questão sobre propósitos do estudo dirigido como estratégia de ensino onde o autor traz recomendações metodológicas didáticas para a estratégia de ensino, de acordo com os objetivos da educação e das normas de ação didática; Abramovich ${ }^{(16)}$ utilizado para formulação das hipóteses das categorias para análise dos resultados da questão 11 (Anexo 1).

Foram realizados dois testes-piloto. Nos quais os sujeitos eram ex-alunos da mesma escola onde foi realizado o estudo e que também vivenciaram o estudo dirigido como estratégia de ensino em sala de aula. Após o teste foram realizadas modificações para adequar a objetividade das questões e sua clareza sem, no entanto, modificar o teor de seus conteúdos. Após este procedimento, ocorreu a aplicação do questionário em data e horário determinados e autorizados pela direção escolar.

O questionário continha questões sobre as características dos alunos e da estratégia aplicada: sexo, idade e trabalho profissional; hábitos e estratégia de estudo individual, das experiências com o estudo dirigido anteriormente e dos recursos de informações utilizadas; sobre os propósitos didático-pedagógicos do estudo dirigido como estratégia de ensino e, por fim, da avaliação geral e as justificativas dos conceitos atribuídos a essa estratégia. As questões foram do tipo fechadas, abertas e mistas. 


\section{Procedimentos éticos}

O projeto de pesquisa foi aprovado pelo Comitê de Ética da mantenedora do local de estudo. Após a assinatura do termo de consentimento pelos alunos interessados em participar do estudo, o questionário foi aplicado no último dia do Curso de Habilitação Profissional de Técnico de Enfermagem, quando todos os conceitos escolares já estavam emitidos, a fim de se evitar constrangimento por parte dos sujeitos participantes da pesquisa e evitar que pensassem que suas respostas pudessem interferir na avaliação e condução do curso. Todos os alunos da turma aceitaram e responderam o questionário no dia determinado, de forma individual e sem interferência docente ou de qualquer outro sujeito.

\section{Análise dos dados}

A identificação com as iniciais dos sujeitos no questionário não foi usada para análise, serviu apenas como recurso de organização dos dados.

Os procedimentos gerais para obtenção e apresentação dos resultados dos dados foram:

- Para as questões $2,3,4,5,7,8,9$ e 10, os dados foram digitados em planilha do programa Excel e apresentados sob a forma de tabelas, quadros e gráficos.

- As respostas da questão 6 foram transcritas em programa Word for Windows, sendo identificadas as unidades semânticas de cada resposta, segundo a técnica proposta por Bardin ${ }^{(17)} \mathrm{e}$, após, classificadas em três quadros: "escolhendo o local onde estudar"; "escolhendo com quem estudar" e "escolhendo a maneira de estudar".

- As respostas da questão 11 foram transcritas em programa Word for Windows, identificadas as unidades de contexto, codificadas, categorizadas, conforme análise de conteúdo descrita por Bardin ${ }^{(17)}$.

- A análise dos resultados foi realizada à luz do referencial teórico de Freire ${ }^{(18)}$.

\section{APRESENTAÇÃO DOS RESULTADOS E ANÁLISE DOS DADOS}

A apresentação, resultados e análise dos dados das questões $2,3,4,5,7,8,9$ e 10 não serão apresentados para este artigo visando o objetivo proposto.

Dos 14 sujeitos envolvidos no estudo, 12 avaliaram o estudo dirigido como boa estratégia de ensino e dois como excelente. As justificativas dos sujeitos aos conceitos atribuídos à estratégia de ensino após a análise do conteúdo das respostas ${ }^{(17)}$, resultou na identificação de $83(100 \%)$ unidades semânticas distribuídas nas categorias: Vantagens,
44 (53\%); Não “Legal”, 13 (16\%); Dificuldades, 6 (7\%); Sentimentos, 10 (12\%) e Sugestões, 10 (12\%).

$\mathrm{Na}$ categoria vantagens, foram identificadas 44 unidades semânticas, sendo expressa a possibilidade dos sujeitos poderem "desenvolver um assunto de seu interesse", seguido do "domínio para preparar e apresentar aquilo que aprenderam" e "aprender por meio de um bom método, descobrindo sua capacidade de saber aprender".

Fatores motivacionais intrínsecos poderiam resumir estas três maiores expressões da categoria vantagens, buscar conhecer seus próprios interesses, ter autoconfiança e autoestima.

Em muitos momentos no desenrolar dos estudos, os alunos desabrocharam para o prazer em buscar o conhecimento e, à medida que o aluno ganhou auto-estima, autoconfiança ao saber que sabia, isto o impulsionou a ser dono do conhecimento para usar algo, que era de seu domínio. É um momento de boniteza $a^{(18)}$.

$\mathrm{Na}$ categoria $O$ que não ocorreu de forma legal, foram citadas 13 unidades semânticas, sendo a condução docente durante o estudo dirigido a mais expressiva.

A análise desse resultado foi atribuída a um mau planejamento do professor em relação às atividades efetuadas, com a condução didático-pedagógica ainda impregnada dos hábitos da pedagogia tradicional. Os sujeitos discorreram muito a respeito disso, e apontaram a necessidade de adaptar a estratégia de ensino às peculiaridades da classe, pois exige maior tempo no cronograma e maior afinidade de papéis.

Entretanto, as justificativas para tais representações levaram-nos a refletir sobre a imposição do novo sobre o velho sistema educacional, das adaptações do novo papel do aluno que antes era passivo e agora ativo em seu processo ensino-aprendizado. ainda com um olhar mais atento e desprovido de qualquer discriminação, preconceitos e julgamentos, posso também buscar compreender cada manifestação desses sujeitos, considerando o momento e a necessidade de cada um.

(....) Saber que não posso passar despercebido pelos alunos, e que a maneira como me percebam me ajuda ou desajuda no cumprimento de minha tarefa de professor, aumenta em mim os cuidados com o meu desempenho. Se a minha opção é democrática, progressista, não posso ter uma prática reacionária, autoritária, elitista. Não posso discriminar o aluno em nome de nenhum motivo. A percepção que o aluno tem de mim não resulta exclusivamente de como atuo mas também de como o aluno entende como atuo. Evidentemente, não posso levar meus dias como professor a perguntar aos alunos o que acham de mim ou como me avaliam. Mas devo estar atento à leitura que fazem de minha atividade com eles. Precisamos aprender a compreender a significação de um silêncio, ou de um 
sorriso ou de uma retirada da sala. O tom menos cortês com que foi feita uma pergunta. Afinal, o espaço pedagógico é um texto para ser constantemente 'lido', interpretado, 'escrito' e 'reescrito'. Neste sentido, quanto mais solidariedade exista entre o educador e educandos no "trato" deste espaço, tanto mais possibilidades de aprendizagem democrática se abrem na escola(18).

As dificuldades foram expressas em seis unidades semânticas, sendo as mais expressivas aquelas relacionadas à coordenação do tempo para o estudo, à insegurança para apresentação dos resultados do estudo, quer no empenho do aluno quer na necessidade de avaliar e discutir a apresentação.

Procurar uma coerência entre o que aprendi e o que devo escolher "para transmitir", como fazer, de que forma avaliar, ser justo, ético comigo e com os outros, todas essas dificuldades são reais no papel ativo do processo de não apenas aprender, mas ensinar. São as dificuldades a serem enfrentadas e desenvolvidas com o professor e envolvem estabelecer diálogo, espaço para expressões verbais e não-verbais.

À respeito da disponibilidade de diálogo, em que essas dificuldades serão tratadas, cita-se:

\section{(....) Preciso, agora, saber ou abrir-me à realidade desses alunos com quem partilho a minha atividade pedagógica. Preciso tornar-me, se não absolutamente íntimo de sua forma de estar sendo, no mínimo, menos estranho e dis- tante dela. E a diminuição de minha estranheza ou de mi- nha distância da realidade hostil em que vivem meus alu- nos não é uma questão de pura geografia. Minha abertura à realidade negadora de seu projeto de gente é uma ques- tão de real adesão de minha parte a eles e a elas, a seu direito de ser. $(. . .)^{(18)}$.}

Esse saber ou abrir-me à realidade dos alunos, são novos desafios que deverão ser enfrentados tanto pelo professor quanto pelo aluno, surgirão outras dificuldades, que só serão solucionadas se houver a participação de todos os atores do cenário da Educação, ao perceberem e proporem o desenvolvimento de habilidades e competências para enfrentá-los.

O fator tempo é limitante dentro de um cronograma, que foi planejado baseado em uma pedagogia tradicional, pois a pedagogia da interação requer maior tempo, sobretudo quando os atores do cenário para esse tipo de educação ainda estão re-aprendendo seus papéis. As fases do processo ensino-aprendizado precisam ser desenvolvidas e adaptadas para que as estratégias de ensino tornem-se mais eficientes e eficazes.

Os sentimentos que surgiram durante o estudo dirigido foram representados por dez unidades semânticas, e as mais citadas foram o sentir que foi muito bom, de gostar da estratégia, de ter medo, de agradecimento ao docente por utilizar a estratégia e também um que não gostou de apresentar trabalho.
(....) É preciso, por outro lado, reinsistir em que não se pense que a prática educativa vivida com afetividade $\mathrm{e}$ alegria, prescinda da formação científica séria e da clareza política dos educadores ou educadoras. A prática educativa é tudo isso: afetividade, alegria, capacidade científica, domínio técnico a serviço da mudança ou, lamentavelmente, da permanência do hoje.(.... $)^{(18)}$.

$\mathrm{Na}$ categoria sugestões, foram identificadas dez unidades semânticas, sendo mais expressiva a necessidade do estudo ser agradável e do interesse para os alunos, para que estes participem de forma ativa e haja uma diversificação das estratégias de ensino durante o curso. Essas sugestões podem ser analisadas como reforços em utilizar estratégias que busquem a motivação, a fim de que o aluno participe de seu processo ensino-aprendizado, envolvendo-se e contribuindo com sua própria formação. Servem como alerta aos professores, que se prendem a uma única estratégia, pois não existe a melhor estratégia, quanto mais a única e, sim, a melhor situação para utilizá-la. Também sugerem a necessidade do sujeito participar de um processo ensinoaprendizado agradável, não entediante, na busca de adaptação a problemática individual a cada proposta de solução didático-pedagógica conjunta, aluno e professor.

\section{(....) É neste sentido que se pode afirmar ser tão errado separar prática de teoria, pensamento de ação, linguagem de ideologia, quanto separar ensino de conteúdos de chama- mento ao educando para que se vá fazendo sujeito do pro- cesso de aprende-los. Numa perspectiva progressista o que devo fazer é experimentar a unidade dinâmica entre o ensino do conteúdo e o ensino de que é e de como aprender. É ensinando matemática que ensino também como aprender e como ensinar, como exercer a curiosidade epistemológica indispensável à produção do conhecimento ${ }^{(18)}$.}

As propostas didático-pedagógicas sugeridas para o estudo dirigido e avaliadas pelos alunos foram: desenvolver no aluno uma metodologia de estudo; facilitar o estudo para o aluno; participação do aluno de seu processo de aprendizado; reconhecer as dificuldades individuais dos alunos; possibilitar as intervenções de forma personalizada pelo professor; favorecer a valorização do conhecimento do aluno; permitir o desenvolvimento de temas de interesse do aluno, respeitar a velocidade e profundidade de estudo para cada aluno; ampliar as fontes de busca do conhecimento científico; estabelecer relações de credibilidade entre aluno e professor; estimular o prazer em estudar e incentivar o aluno a ser o sujeito de seu próprio aprendizado. Esses propósitos receberam nota de 1 a 4: em que 1 representava não contemplou a proposta e 4 contemplou ao máximo a proposta pedagógica do estudo dirigido.

Os propósitos didático-pedagógicos mais contemplados com nota 4 nesta avaliação foram: permitir o desenvolvimento de temas de interesse pelo aluno; estimular o prazer para estudar; incentivar o aluno a ser o sujeito de seu aprendizado. Esses resultados nos proporcionaram os principais 
propósitos didático-pedagógicos para aplicação do estudo dirigido como estratégia de ensino.

Os propósitos didático-pedagógicos não contemplados foram não facilitar o estudo para o aluno e não respeitar a velocidade e profundidade de estudo para cada aluno. Apesar desse resultado, não podemos concluir que haja impedimentos na aplicação da estratégia para esses propósitos didático-pedagógicos, visto que entendemos, dependerá do estágio de desenvolvimento do aluno e do professor, segundo suas habilidades e competências para desempenhar sua função e ou atividade.

Para proporcionar um ensino efetivo e capaz de atender às necessidades de formação do aluno em sala de aula e transpor essas relações e exercícios ao mundo do trabalho, as propostas didático-pedagógicas precisam ser objetivas e claras para todos os envolvidos no processo educacional. Assim sendo, contemplamos, nesta experiência, o que exigem os momentos históricos, políticos, filosóficos e sociais nos quais as escolhas das estratégias de aula dos professores estão inseridas ${ }^{(13,19)}$.

\section{CONSIDERAÇÕES FINAIS}

A análise dos resultados da pesquisa permitiu considerar que o estudo dirigido como estratégia de ensino favorece o desenvolvimento de uma pedagogia em que $o$ aluno é o centro de todas as atividades ${ }^{(2)}$, desenvolvendo temas de seu interesse, aprendendo a aprender, descobrindo o prazer para aprender e sendo sujeito de suas ações, como resultado do processo ensino-aprendizado.

\section{REFERÊNCIAS}

(1) Vilela VV. Estratégias para enriquecer o aprendizado. [online] Disponível em: <http://www.mapasmentais.com.br> [Acesso em 12 set. 2002].

(2) Godoy A. Renovação dos métodos e técnicas de ensino em enfermagem na escola de enfermagem da Universidade de São Paulo. Rev Bras Enferm. 1968;21(4):227-30.

(3) Horta WA, Sivieri MC, Paula NS, Hara Y. Renovação dos métodos e técnicas de ensino em "fundamentos de enfermagem" na escola de enfermagem da Universidade de São Paulo. Rev Bras Enferm. 1968;21(4):231-44.

(4) Sanna MC, Cunha ICKO, Campos JP. Estratégias inovadoras no ensino de administração aplicada à enfermagem. Rev Paul Enferm. 1999;18(1/3):16-26.

(5) Brasil. Ministério da Educação e Cultura. Lei n. 9.394 de 20, de dezembro de 1996. Estabelece as diretrizes e bases da educação nacional. Brasília. Diário Oficial da República Federativa do Brasil, Brasília, 23 dez. 1996. Seção 1, p. 27833-41.
A pesquisa possibilitou verificar as atenções didáticopedagógicas do professor em seu planejamento e organização da estratégia de ensino perante o que o aluno colocou como Não Legal, de suas dificuldades e sentimentos surgidos durante o desenvolvimento do estudo dirigido.

Pelo teor das respostas obtidas na pesquisa, constatamos a competência técnica e responsável desses alunos ao participarem da avaliação do que vivenciaram e ainda por se mostrarem comprometidos em sugerir ações para melhorar os resultados do processo ensino-aprendizado em sala de aula.

Todo esse movimento de agir e refletir sobre o ensino com professor e aluno foi proporcionado pelo desenvolvimento de uma estratégia de ensino dentro de uma política educacional, demonstrando não só o poder dos alunos em Ser e não apenas Fazer uma atividade, como a de exercitar relações e ações que, acreditamos, irão transpor as portas da escola pela prática profissional, tanto em nível de trabalho em equipe quanto de assistência à saúde, (...) tendo em vista formar um cidadão consciente, crítico e participante ${ }^{(20)}$.

Planejar, aplicar e avaliar uma estratégia de ensino é respeitar limites e permitir crescer com a participação daquele que sempre esteve passivo em seu processo ensino-aprendizado. Trata-se de tarefa árdua, mas, sem dúvida enriquecedora, a cada descoberta por meio de olhares de deslumbramento dos alunos em se (re)descobrirem como sujeitos da ação, da participação consciente, crítica. Pela responsabilidade de construir e retomar o aprender a Ser, Conviver, Conhecer e Fazer o aluno e o professor crescerem, ganham todos, pois nesta relação vigora o respeito em ouvir, olhar e sentir um ao outro, o que com certeza, irá se refletir na assistência à saúde daquele que busca na Enfermagem sentimentos e ações responsáveis pela qualidade de vida.

(6) Conselho Nacional de Educação. Parecer CNE/CEB n. 16, de 26 de outubro de 1999. Dispõe sobre as Diretrizes Curriculares Nacionais para Educação Profissional de Nível Técnico. Conselho Nacional de Educação [online]. Brasília, 22 nov. 1999. Disponível em: http://portal.mec.gov.br/cne/index.php?option= content $\&$ task=view\&id=147\&Itemid=206\#1999B [Acesso em 09 abr. 2004].

(7) Piletti C. Didática geral. São Paulo: Ática; 1990.

(8) Mascaretti LAS. Estratégias de ensino: considerações gerais. In: Marcondes E, Gonçalves EL. Educação médica. São Paulo: Sarvier; 1998. p. 187-8.

(9) Nérici IG. Didática geral dinâmica. 11ª ed. São Paulo: Atlas; 1992.

(10) Libâneo JC. Didática. 2a ed. São Paulo: Cortez; 1994.

(11) Lobo Neto FJS. Educação. Rio de Janeiro: Fundação Oswaldo Cruz; 2000. (Formação Pedagógica em Educação Profissional na Área de Saúde: enfermagem; módulo 1). 
(12) Torrez MNFB, Romano RAT, Pimentel MRAR, Goulart VPM. Planejando uma prática pedagógica autônoma e significativa em enfermagem. Rio de Janeiro: Fundação Oswaldo Cruz; 2000. (Formação Pedagógica em Educação Profissional na Área de Saúde: enfermagem; módulo 10).

(13) Torrez MNFB, Romano RAT, Pimentel MRAR, Goulart VPM. Vivenciando uma ação docente autônoma na educação profissional em enfermagem. Rio de Janeiro: Fundação Oswaldo Cruz; 2000. (Formação Pedagógica em Educação Profissional na Área de Saúde: enfermagem; módulo 11).

(14) Polit DF, Hungler BP. Fundamentos de pesquisa em enfermagem. $3^{\text {a }}$ ed. Porto Alegre: Artes Médicas; 1995.

(15) Thiollent MJM. Crítica metodológica: investigação social \& enquête operária. São Paulo: Polis; 1980.
(16) Abramovich F. Quem educa quem? São Paulo: Summus; 1985.

(17) Bardin L. Análise de conteúdo. Lisboa: Edições 70; 1977.

(18) Freire P. Pedagogia da autonomia: saberes necessários à prática educativa. $15^{\text {a }}$ ed. São Paulo: Paz e Terra; 2000.

(19) Bagnato MHS. Concepções pedagógicas no ensino de enfermagem no Brasil. Texto Contexto Enferm. 1997;6(3):241-58.

(20) Silva MJL. Um aspecto da função ideológica da escola: o currículo oculto. Bol Técnico Senac. [periódico online] São Paulo 2001. Disponível em: http://www.senac.br/boletim/ boltec10.htm > [Acesso em 16 jul. 2001].

\section{ANEXO1}

\section{INSTRUMENTODECOLETA}

Prezado (ex) aluno,

Com o objetivo de verificar sua opinião sobre o estudo dirigido, utilizado durante sua formação como Técnico de Enfermagem, solicito que você responda às questões abaixo com sinceridade.

Agradecemos a sua participação.

Identificação:

1. Iniciais do nome: $\quad$ 2. Idade: __anos $\quad 3$ Sexo: Masculino ( ) Feminino ( )

4. Você trabalha: Sim ( ) Não ( ) Esporadicamente ( )

Há quanto tempo?___ Em que período: Qual atividade:

5. Você estuda fora do horário da escola? Sim ( ) Não ( )

Com que freqüência? Por quanto tempo? Em que local?

6. Relate sucintamente qual é a sua melhor forma de estudar:

7. Você já havia participado anteriormente de um estudo dirigido?

( ) Sim. Quando? _ _ ( ) Não me lembro ( ) Não sei ( ) Foi a primeira vez

8. Que recursos você busca como fonte de informações?

( ) Apostilas ( ) Livros particulares ( ) Recursos através da biblioteca ( ) Internet

( ) Outras fontes. Quais: 
(continuação)

9. Conceitue de um a quatro a nota dada ao propósito atingido ou não pela estratégia estudo dirigido considerando sua experiência de aprendizado durante a Disciplina de Saúde do Adulto. A saber, nota 1 para não atingiu aos propósitos e nota quatro para a contemplação máxima deste propósito pela estratégia sob seu ponto de vista.

\begin{tabular}{|l|l|}
\hline Propósitos do estudo dirigido como estratégia de ensino & Nota (1, 2, 3 ou 4) \\
\hline Desenvolver no aluno uma metodol ogia de estudo & \\
Facilitar o estudo para o aluno & \\
Partipar o aluno do seu processo de aprendizado & \\
Reconhecer dificuldades individuais dos alunos & \\
Possibilitar intervenções de forma personalizada pelo professor das dificuldades no processo de & \\
aprendizado pelo aluno & \\
Favorecer a valorização do conhecimento do aluno & \\
Permitir desenvolver temas de interesse pelo aluno & \\
Respeitar a velocidade e profundidade de estudo para cada aluno & \\
Ampliar as fontes de buscar conhecimentos científicos & \\
Estabelecer relações de credibilidade entre o aluno e professor & \\
Estimular o prazer em estudar & \\
Incentivar o aluno a ser o sujeito de seu aprendizado & \\
\hline
\end{tabular}

10. Você avalia esta estratégia de ensino

( ) Excelente ( ) Boa ( ) Regular ( ) Insatisfatória

11. Comente a questão 10 (sobre as vantagens, facilidades, sentimentos, o que gostou de fazer, o que foi "chato", o que foi incrível, o que não ocorreu de forma "legal", enfim justificativas e/ou critérios que utilizou para chegar a um conceito final para a estratégia de ensino), sobre o estudo dirigido como estratégia de ensino durante a Disciplina Saúde do Adulto. Dê sugestões de como seu aprendizado possa vir a ser melhorado. 